\title{
VIOLÊNCIA CONTRA CRIANÇAS E ADOLESCENTES NO AMAZONAS: ANÁLISE DOS REGISTROS
}

\author{
Angela Costa Maia \\ Maíra Barreto
}

\begin{abstract}
RESUMO. A violência contra crianças e adolescentes é um fenômeno frequente, mas pouco se conhece sobre o contexto em que ocorre e sobre suas consequências. O objetivo deste estudo é caracterizar esta violência no Interior do Estado do Amazonas. Foram analisados 193 registros do Relatório Txain sobre a Violência contra Crianças e Adolescentes. Como resultado, verificou-se que grande parte dos registros oficiais omitem informações. A agressão física é o tipo de violência mais relatado, e a maior parte das vítimas é constituída de adolescentes do sexo feminino de idades entre 12 e 15 anos. Os agressores são predominantemente desconhecidos das vítimas e são do sexo masculino. Em termos de consequências para a saúde, há referência a algumas lesões físicas, mas os dados são bastante omissos em relação à saúde mental. Estes dados sugerem a necessidade de integralização e aprimoramento dos sistemas de registro, informação e atendimento a vítimas fora das grandes cidades.
\end{abstract}

Palavras-chave: Adolescentes; crianças; violência.

\section{VIOLENCE AGAINST CHILDREN AND ADOLESCENTS IN AMAZONAS: ANALYSIS OF THE REPORTS}

\begin{abstract}
Introduction: Violence against children and adolescents is a widespread phenomenon, but little is known about the contexts in which it occurs and its consequences. The objective of this study was to characterize violence in the inner state of Amazonas. Method: We analyzed 193 records from Txain Report on Violence against Children and Adolescents. Results: Most of the official records have missing information. Physical abuse is the most frequently reported type of violence, and most victims are female, between 12 and 15 years. The perpetrators are predominantly male and unknown from victims. Regarding health consequences, there is reference to some injuries, but the data are quite lacking in relation to mental health. Conclusion: These data suggest the need of improvement in the registration, information and intervention procedures outside of large cities.
\end{abstract}

Key words: Adolescents; children; violence.

\section{VIOLENCIA CONTRA LOS NIÑOS Y ADOLESCENTES EN EL AMAZONAS: ANÁLISIS DE LOS REGISTROS}

RESUMEN. Introducción: La violencia contra los niños y adolescentes es un fenómeno generalizado, pero se sabe poco sobre el contexto en el que se produce y sus consecuencias. El objetivo de este estudio fue caracterizar la violencia contra los niños en el estado de Amazonas. Método: Se analizaron 193 registros del Informe Txain sobre la Violencia contra los Niños y adolescentes. Resultados: Los registros oficiales no dicen nada acerca de un montón de información. El abuso físico es el tipo más frecuente de violencia, y la mayoría de las víctimas son mujeres, entre 12 y 15 años. Los autores son predominantemente desconocidos de las víctimas y hombres. En términos de consecuencias para la salud, se hace referencia a algunas lesiones físicas, pero los datos son muy escasos en relación con la salud mental. Conclusión: Estos datos sugieren la necesidad de la integración y la mejora del sistema de registro, información y atención fuera de las grandes ciudades.

Palabras-clave: Adolescentes; niños; violencia.

Doutora em Psicologia Clínica, coordenadora do Mestrado Integrado em Psicologia da Saúde, investigadora da Unidade de Investigação de Justiça e Violência, professora auxiliar na Escola de Psicologia da Universidade do Minho, Portugal.

Graduação em Psicologia pela Universidade Federal do Amazonas, pós-graduação em Terapia Comunitária. 
A violência está presente em todas as culturas, nos dois gêneros e nas diferentes classes sociais, etnias e faixas etárias. Ela atinge tanto os países ricos como os pobres, embora seja mais notória nos países onde as condições de vida são mais precárias. De acordo com os dados da Organização Mundial de Saúde (Dahlberg \& Krug, 2002), a violência é uma das principais causas de morte entre os 15 e os 44 anos, mas existem várias assimetrias regionais, de forma que a África e a América Latina apresentam índices muito superiores ao de outras áreas do globo. No Brasil a violência tem sido uma das principais causas de morte entre os 5 e os 49 anos (Souza \& Minayo, 1994).Nos anos 90 do século XX o reconhecimento da violência enquanto problema de saúde pública levou a $49^{\mathrm{a}}$ Assembleia Mundial de Saúde a propor uma resolução que declara a violência como o maior e mais crescente problema de saúde no mundo (WHO, 1996).

De modo geral, a violência é a negação, a usurpação e a violação das condições físicas, psíquicas, intelectuais, morais e de liberdade que garantem a vida em sociedade das pessoas, seja nas relações interpessoais seja nas coletivas. Desse modo, o conceito de violência inclui-se como objeto do Direito, uma vez que tem como referência o ato de ferir valores e princípios de convivência, gerando a injustiça, a infelicidade, a exclusão, a discriminação, a privação material e a privação da liberdade (de expressão, de religião, do exercício de uma cultura) e de convivência social equânime (Hayasida, 2005).

Vários modelos têm sido utilizados para explicar a violência, mas desde a década de 70 do século XX o modelo ecológico de Brofenbrenner (1979), mais recentemente revisto e designado por modelo bioecológico (Bronfenbrenner \& Morris, 1998), tem sido utilizado para integrar a multiplicidade dos fatores que contribuem para a prática da violência. Este modelo considera tanto fatores relacionados com as características individuais, onde se incluem as características biológicas, psicológicas e de história pessoal (exemplo, impulsividade, doença mental, uso de substâncias, história de abuso) quanto fatores relacionais, onde se inserem as qualidades das relações familiares e de pares. Sabe-se que em famílias marcadas pela agressividade e em contextos sociais em que os amigos têm comportamentos violentos, a probabilidade de ser vítima ou perpetrador de violência aumenta. As características da comunidade e os valores e organização da sociedade mais ampla são os outros níveis em que se podem analisar os fatores de risco de violência.

Em relação à comunidade, as características das escolas e dos contextos de trabalho, a pressão demográfica, a organização geográfica desorganizada ou mal planeada e a má qualidade dos espaços podem levar à violência. A falta de recursos sociais e de instituições de apoio, a baixa coesão social ou o isolamento social são igualmente fatores de risco. Finalmente, o modelo ecológico mostra, em nível mais amplo, que a cultura, os valores e as atitudes e normas sociais são determinados pelo contextos culturais e políticos e definem o que é aceitável e está vigente em cada momento numa sociedade. Sabe-se que há contextos sociais e culturais que potenciam e viabilizam práticas violentas.

A probabilidade de ocorrer violência, em cada momento, depende de quantos fatores de risco estejam presentes, e o mesmo comportamento violento pode dever-se, em diferentes contextos, a diferentes fatores. No Brasil vários investigadores têm publicado trabalhos em que o modelo bioecológico é aplicado para compreender as condições que estão associadas a fenómenos de violência (e.g. Cecconello, \& Koller, 2003; Poletto \& Koller, 2008; Prati, Couto, Moura, Poletto, \& Koller, 2008).

Aqui interessa tratar a violência contra crianças e adolescentes ocorrida nos espaços cotidianos.

\section{A SAÚDE E A VIOLÊNCIA CONTRA AS CRIANÇAS E ADOLESCENTES}

A violência contra crianças e adolescentes existiu ao longo de toda a história da humanidade e a preocupação com crianças e jovens é recente, principalmente no Brasil (Lorenzi, 2007). A criança e o jovem passaram a ter um estatuto próprio (Estatuto da Criança e do Adolescente - ECA) na Lei 8.069/90, que contempla os mais avançados dispositivos normativos internacionais dos direitos da população infanto-juvenil (Bezerra, 2006; Carvalho, 2010).

No Brasil, não se pode falar em criança e adolescente sem que se lembre de violência. Segundo estudos epidemiológicos e sociológicos, eles ainda se encontram expostos e vulneráveis (Ministério da Saúde, 2004). A violência causa transtornos não apenas físicos, mas também emocionais e psicológicos, afetando o bem-estar e a qualidade de vida das vítimas (Weaver' \& Clum, 1995). Nas crianças e adolescentes vítimas de violência alguns dos transtornos são mais aparentes, como os sintomas físicos, enquanto outros são mais difíceis de perceber, mais subjetivos. Vários estudos comprovam que esta experiência afeta profundamente a vida das vítimas, deixando marcas negativas no seu desenvolvimento pessoal, social, sexual, escolar e no seu funcionamento psíquico, aumentando o risco de prostituição, 
drogadição, transtornos psicológicos, suicídio e reedição da violência, entre outros efeitos. Por exemplo, o relatório da Organização Mundial de Saúde sobre Violência e Saúde (2002) salienta entre as consequências psicológicas e comportamentais o abuso de álcool e drogas; depressão e ansiedade; atrasos no desenvolvimento; distúrbios do sono; sentimentos de culpa e vergonha; hiperatividade; mau desempenho escolar; baixa autoestima; transtorno de estresse pós-traumático; distúrbios psicossomáticos; comportamento suicida e automutilação; agressividade; condutas sexuais inadequadas; dificuldades nos relacionamentos interpessoais; distúrbios alimentares; distúrbios afetivos (apatia, desinteresse pelas brincadeiras, crises de choro); dificuldades de adaptação; envolvimento com prostituição; mudanças de comportamento e de vocabulário.

Apesar de se reconhecer que a vitimização de crianças e adolescentes não é um fenômeno raro no Brasil, e de se conhecer o impacto destas experiências sobre as suas vítimas, a caracterização dos fenômenos de violência que atingem as crianças são grandemente desconhecidos, especialmente se considerarmos zonas do interior. Conquanto se saiba que uma parte significativa da violência não é denunciada nem pelas vítimas nem por outros, e por isso não é conhecida, a caracterização dos casos que são denunciados pode contribuir para melhor se compreender o fenômeno da violência contra crianças e adolescentes.

$\mathrm{O}$ objetivo desta pesquisa foi conhecer melhor as situações de violência contra as crianças e adolescentes, identificando o perfil das vítimas, os tipos de violência que sofreram, o perfil dos agressores e denunciantes e os impactos de ordem física e psicológica sobre as vítimas. Este estudo foi feito a partir dos registros feitos em delegacias e fóruns de justiça no interior do Estado do Amazonas, no período de uma década (1992 - 2002). O município a que se referem os dados desta pesquisa tem 57.230 $\mathrm{km}^{2}$, com uma população - segundo o censo realizado pelo IBGE (2000) - de cerca de 70.000 habitantes, em sua maioria pessoas que moram em áreas definidas como urbanas.

Nessa cidade houve uma importante obra de infraestrutura na década de noventa, com grandes impactos sobre a economia, a sociedade e o ambiente (Gawora, 2003), uma vez que ocorreu um aumento do fluxo migratório devido à grande expectativa econômica. Estas mudanças acarretaram um vertiginoso aumento da violência, da prostituição e do tráfico de drogas, segundo Gawora (2003).

\section{MÉTODO}

\section{Dados}

O presente estudo utilizou-se de dados coletados no Relatório da Pesquisa sobre a Violência Sexual com Crianças e Adolescentes no Amazonas (2009), trabalho realizado com o apoio do IPAM/UNICEF/Ministério da Justiça. Estes dados são procedentes das delegacias de polícia (militar e civil), das promotorias, das varas e fórum de justiça e dos conselhos tutelares do município pesquisado. Os dados analisados são referentes à década de 1992 a 2002, tendo sido encontrados, ao todo, 193 registros.

\section{Procedimentos}

Os dados foram inicialmente recolhidos em vários municípios do Amazonas por técnicos que elaboraram o relatório TXAIN (Barreto, 2009), o qual procurava fazer um levantamento dos registros de prostituição infanto-juvenil. Essa pesquisa originou diversas bases de dados sobre violência em geral que não foram tratadas com vista aos impactos nas vítimas das diversas formas de violência.

Para este trabalho inicialmente fez-se uma leitura de todo o Relatório TXAIN e das bases de dados, para se saber o tipo de informação de cada caso. A partir desta leitura foi feita uma grelha, que foi utilizada para análise de cada caso e preenchida com informações de dois tipos, dos quais o primeiro contempla o tipo de violência e o local onde ocorreu, bem como as características das vítimas, dos agressores e dos denunciantes, e o segundo tipo de informações procura caracterizar as consequências para a saúde física e psicológica da experiência da violência nas vítimas.

\section{RESULTADOS}

\section{Evolução ao longo do tempo}

Os números apresentados indicam que há uma grande oscilação nos registros de casos de violência ao longo do tempo, embora pareça haver uma visibilidade crescente sobre o problema. Em 1992 foram registrados seis casos (3,11\%); em 1994, 12 casos (6,24\%); em 1996, 24 casos (12,44\%); em 2000, 30 casos $(15,54 \%)$; e em 2002, 50 casos $(25,91 \%)$ - o que sugere um aumento contínuo; mas na verdade, em 1993 e 1999 conta-se apenas um caso e em 2001, quinze casos (muito menos que nos anos anterior e posterior), no total de 193 casos registrados. 


\section{Tipologia da violência}

Em relação à tipologia da violência considera-se o tipo de crime que está registrado, embora num grande número de vítimas a leitura dos processos permita verificar que o agressor cometeu mais de uma modalidade de crime contra a vítima.

No município em foco foram coletados casos de agressão física, ameaças de todas as formas, raptos, desaparecimentos, tentativas de estupro, estupro, abuso sexual, atropelamento, aliciamento, calúnia e difamação. Para a análise dos resultados os dados foram agrupados a partir dos registros originais. Grande parte dos casos registrados é de agressão física, que aparece em 49 dos casos (25,39\%). Desses casos de agressão, seis foram acompanhados de maustratos físicos, furto e ameaças. Três casos de agressão física incluem abuso sexual e são acompanhados de aliciamento. Entre os casos de agressão, um envolve maus-tratos físicos praticados pelo pai contra uma criança menor de quatro anos e em dois casos as vítimas foram presas em flagrante, por roubo.

O estupro é outra das formas de violência com números próximos aos casos de agressão, com 48 casos $(24,87 \%)$; as tentativas de estupro compreendem $46(23,83 \%)$ casos; e as ameaças - que englobam ameaças de morte e de sequestro - compreendem 26 casos $(13,47 \%)$.

\section{Local}

Nas residências das vítimas ocorreram 34 $(17,62 \%)$ das situações. Pelos dados examinados nesta pesquisa constata-se que uma grande percentagem dos casos de violência ocorre em via pública, com 52 casos $(26,94 \%)$. Na residência do agressor também foram encontrados seis casos $(3,11 \%)$ do total de 193 registros de vítimas. Em locais privados contam-se também os que ocorreram no local de trabalho, particularmente contra jovens que eram empregadas domésticas; em motéis e casas noturnas da cidade, contam-se quinze $(7,77 \%)$ crimes sexuais. Apenas duas $(1,04 \%)$ situações ocorreram em local desconhecido. A omissão da informação sobre o local ocorre em uma percentagem muito elevada de casos $(43,52 \%)$, correspondendo a 44 situações registradas.

\section{Características das vítimas}

A maioria das vítimas $(169,87,56 \%)$ é do sexo feminino e um muito menor número $(24=12,44 \%)$, do sexo masculino.

Em relação às idades das vítimas de violência, do total de 193 , cinco $(2,59 \%)$ têm até três anos de idade; $10(5,18 \%)$ têm entre quatro a sete anos; $20(11,39 \%)$ estão na faixa de oito a 11 anos. A maioria é adolescente, uma vez que 81 (41,97\%) encontram-se na faixa de idade compreendida entre 12 e 15 anos e $66(34,20 \%)$ têm entre 16 e 19 anos de idade.

A situação de escolaridade e ocupação das vítimas é omitida na maioria dos casos $(127,65,80 \%)$. As vítimas que declaram ser estudantes somam 30 $(15,54 \%)$, e são $16(8,29 \%)$ as vítimas que não exercem nenhum tipo de ocupação remunerada e quatro $(2,07 \%)$ as que têm emprego remunerado.

Em 10 casos $(5,18 \%)$ é referido que as vítimas já vinham sofrendo violência, enquanto em 44 (22,80\%) dos casos a vítima sofreu violência pela primeira vez. Finalmente em $139(72,02 \%)$ casos esta informação não está nos registros.

\section{Características dos agressores}

Os registros correspondem a 193 vítimas e 210 agressores, uma vez que alguns casos envolveram vários agressores a cometer um crime; nesses casos não consta nenhum tipo de informação sobre esses agressores.

Em relação ao sexo dos agressores, $161(76,67 \%)$ são do sexo masculino e $20(9,52 \%)$ do sexo feminino.

Não existem informações sobre a idade do agressor em $200(95,24 \%)$ casos. Dos dados conhecidos, na faixa de 14 a 20 anos há três agressores $(1,43 \%)$, e o mesmo índice se verifica na faixa de 21 a 31 anos. Na faixa de 45 a 66 anos há quatro $(1,90 \%)$ agressores.

Quanto ao relacionamento existente entre o agressor e a vítima, em 29 (13,81\%) casos não há nenhuma informação. Em $71(33,81 \%)$ casos essa relação é marcada pelo termo "conhecido da vítima". Em três $(1,43 \%)$ casos o agressor é o pai, enquanto os parentes da vítima (tios, irmãos, avós) são quinze $(7,14 \%)$ dos agressores. Em grande número de casos $(85=40,48 \%)$, os agressores são desconhecidos das vítimas.

Em relação ao número de agressores, em 151 casos $(78,24 \%)$ as vítimas sofreram violência por um agressor. Em 11 casos $(5,70 \%)$ os agressores variaram entre dois e sete. Sobre $31(16,06 \%)$ casos não há essa informação.

\section{Características dos denunciantes}

Do total de 193 denunciantes encontrados nos registros, $82(42,49 \%)$ são do sexo feminino e em 26 casos $(13,47 \%)$ a denúncia foi pelo sexo masculino. Em 85 casos $(44,04 \%)$ não há informações sobre o sexo dos denunciantes.

Em relação à idade, $52(26,94 \%)$ denunciantes estão na faixa de 12 a 19 anos, o que representa um dos maiores percentuais em comparação com as 
demais faixas de idade organizadas. Desses 52 denunciantes, 38 são as próprias vítimas. Tal como acontece em outros dados, 90 (46,63\%) dos registros não têm informação sobre a idade dos denunciantes.

De modo geral, no que diz respeito à ocupação do denunciante, foram encontrados os seguintes dados: em $11(5,70 \%)$ casos o denunciante era agricultor; 28 $(14,51 \%)$ denunciantes eram domésticas, isto é, realizavam trabalhos do lar, na própria residência. Com emprego fixo foram encontrados 14 (7,25\%) denunciantes. $\mathrm{O}$ número de casos sem informação foi de $125(64,77 \%)$ no total de 193 casos registrados.

\section{Consequências para a saúde}

Em relação à saúde física foram obtidos os seguintes dados: sete vítimas $(3,45 \%)$ estavam em gestação e 56 registros $(27,59 \%)$ acusavam lesões em geral. Queixas de saúde (dor de cabeça, dores abdominais, dores pelo corpo, febre, doenças sem diagnóstico médico) estão registradas em 15 (7,39\%) casos. Acerca de um grande número das vítimas (125, $61,58 \%$ ) não existe informação sobre esta questão.

Ao nível das consequências psicológicas o número de registros sem informação é de 115 $(41,67 \%)$. Os dados encontrados em 78 casos mostram cinco $(1,81 \%)$ vítimas que relataram alguma alteração alimentar. Sabe-se ainda que, após a violência, sete $(2,54 \%)$ vítimas passaram a consumir álcool e drogas e $49(17,75 \%)$ relataram sentir medo (de sair de casa, de reviver a violência). Encontravam-se em estado de choque 50 $(18,12 \%)$ vítimas, enquanto $20(7,25 \%)$ relataram dificuldade de relacionamento (desinteresse, mudança de comportamento, apatia, crises de choro). Em $17(6,16 \%)$ casos as vítimas apresentaram comportamentos impulsivos e agressividade com os familiares e 10 (3,62\%), transtorno sexual (envolvimento com prostituição). Há o registro de que três $(1,09 \%)$ vítimas tinham sentimento de culpa.

\section{DISCUSSÃO}

O objetivo desta pesquisa foi caracterizar o perfil das vítimas de violência em um município do Interior do Brasil, focando as vítimas crianças e adolescentes, como também conhecer os denunciantes e os agressores. O outro objetivo foi descrever os impactos de ordem física e psicológica sobre as vítimas. Estes objetivos teriam sido alcançados com mais êxito se não houvesse tantas lacunas nos dados (WHO, 2002).
Nesse município, o número de casos relatados ás autoridades, por ano, tem uma configuração oscilante, com tendência ascendente; mas essa configuração pode não revelar um aumento da violência, mas aumento do número das denúncias. Existem barreiras culturais, econômicas e sociais à realização de uma denúncia, e tem havido um esforço de mobilização que se organiza em torno da violência no sentido de reprimi-la, dando-lhe uma maior visibilidade. Como resultado há um aumento de alerta das instituições sociais no sentido de repressão, de sanção e de prevenção à violência. Os números indicam que há uma visibilidade crescente sobre o problema. Cabe esclarecer que no ano de 1999 os números são baixos devido à perda de alguns dados, pois o município passou por algumas mudanças estruturais e nesse processo alguns dados ficaram perdidos.

As características da violência que se torna oficialmente reconhecida, no que diz respeito às modalidades e à circunstância em que ocorre, mostram que ela se dá de diferentes modos. Ao contrário da maioria dos estudos, os quais focalizam apenas a violência sexual, excluindo outros aspectos da violência cometidos contra essa população (Finkelhor, Ormrod, Turner, \& Hamby, 2005), o presente estudo não se limitou a caracterizar esse tipo de violência.

Para estabelecer melhores critérios de classificação da violência e circunstanciar melhor o crime, é importante caracterizar a sua natureza. No município em estudo, a maioria dos casos denunciados é de agressão física, embora a agressão sexual também esteja presente.

A maioria dos casos de violência ocorreu em via pública, como as ruas da cidade dentro do perímetro considerado urbano, estradas desertas e em torno dos bares. É em torno das casas noturnas que capeiam a prostituição e a violência. Como os negócios noturnos são prolíferos em rendimentos, outros estabelecimentos surgem repletos de menores que são facilmente vitimáveis. Tal como proposto pelo modelo bioecológico, há condições físicas que propiciam a violência (Bronfenbrenner \& Morris, 1998). De modo geral, acredita-se que o espaço familiar é seguro e menos propício à violência que os espaços das ruas, porém na residência da vítima ocorreram 34 casos, mostrando que ela faz parte do cotidiano da organização familiar. $\mathrm{Na}$ verdade, a violência intrafamiliar é um problema muito comum, e pode ser analisado segundo o modelo ecológico de Broffenbrenner. Recentemente De Antonie e Koller (2010) publicaram um estudo em que analisam a violência familiar a partir deste modelo e salientam como a presença de vários níveis de fatores de risco 
potenciam a ocorrência de atos violentos entre os membros da própria família.

\section{Características das vítimas}

A maioria das vítimas de crimes que foram denunciados é do sexo feminino e adolescente. Entre um e seis anos faz-se a construção da identidade e das formas de relação que a criança vai estabelecer com o mundo. A intervenção do agressor interfere decisivamente neste processo, fazendo-a compreender que o mundo exterior que a cerca tem um caráter agressivo e ameaçador. Conforme os estudos de Piaget (1936), até os seis anos a criança não percebe a distinção que há entre ela e o mundo, não tem autonomia de pensamento ou apropriação suficiente da realidade em si. Nesse momento a criança está inteiramente exposta ao comando do agressor. $\mathrm{Na}$ faixa de 8 a 11 anos a capacidade de pensar se complexifica, mas, devido às características do pensamento operatório concreto, ainda não é claro qual o significado da acções. Apenas mais tarde as vítimas têm uma compreensão mais alargada do mundo, ou seja, é na faixa de idade compreendida entre 12 e 15 anos que o adolescente começa a compreender realmente o que ocorre com ele. É nesse momento que o pensamento deixa de ficar preso ao mundo das coisas, ocorrendo o que Piaget chama de "desmaterialização do pensamento", sua relativa autonomia em relação ao mundo exterior (Piaget, 1936). É o momento em que a vítima se dá conta do que ocorre com ela, o que aumenta a probabilidade de denunciar, e não necessariamente porque a violência seja menor nas faixas de idade anteriores, embora se saiba que a violência sexual é maior contra as adolescentes. As denúncias partem das próprias vítimas, em sua maioria, nesta faixa de idade até os 19 anos.

Grande parte dos registros não dá outras informações das vítimas senão aquelas relacionadas com os atos cometidos pelo agressor. Sua vida social, o modo como vive, o estudo, sua situação emocional e física ficam na obscuridade. É o que acontece com os dados da escolaridade e de ocupação, em que 127 registros estão sem essa informação. A vida da criança, sua família, escolaridade e seu tipo de ocupação não fazem parte do elenco das preocupações dos órgãos, principalmente das delegacias de polícia.

\section{Características dos agressores}

O perfil do agressor é difícil de ser definido. Um dos motivos é a escassa informação nos registros dos casos, pois na maioria das vezes esse perfil permanece na penumbra, passando como "agressor desconhecido".

Nos casos em que há dados, a maioria dos agressores é do sexo masculino. Segundo Finkelhor (1994), o homem é socializado para valorizar os seus interesses sexuais isolados do contexto de uma relação, mas abordagens mais recentes salientam atitudes e valores culturais que validam o exercício do poder por parte do homem e legitimam o uso da força que as teorias feministas têm denunciado (Machado \& Dias, 2010). Quanto à idade do agressor geralmente não há informação, pois as informações sobre os agressores são conhecidas por completo somente quando o processo judicial prossegue para outras instâncias judiciais. Por outro lado, nos casos em que há vários agressores, os registros somente citam a quantidade de agressores e não fornecem nenhum tipo de informação sobre eles.

$\mathrm{O}$ relacionamento existente entre o agressor e a vítima constitui-se em outro dado que permite circunstanciar a violência cometida contra crianças e jovens. O aumento da proximidade faz com que aumente a probabilidade do desenvolvimento de danos para a saúde física e mental (Ballone, s.d). No caso desta pesquisa, uma grande parte dos agressores sobre os quais há informação é desconhecida da vítima.

Lamentavelmente, os registros apresentam muitas falhas sobre os agressores. Frequentemente os abusadores não se limitam a abusar de uma única pessoa ou da mesma pessoa uma só vez. Embora as ocorrências dos abusos possam limitar-se a um único episódio, o mais comum é que a prática se repita várias vezes e dure meses ou anos.

\section{Características dos denunciantes}

O desenvolvimento deste item tem como propósito conhecer, por meio dos dados sobre os denunciantes, quem é que protege ou tenta proteger as vítimas de violência, quem são os denunciantes, quais as relações que esses denunciantes têm com as crianças e adolescentes vítimas de violência e qual o tipo de ocupação que exercem.

Quando se analisa o perfil dos denunciantes, verifica-se que estes são, em sua maioria, do sexo feminino, da faixa etária, predominantemente, de 15 até 19 anos de idade, e em 38 casos são as próprias vítimas.

\section{Consequências para a saúde}

Os dados encontrados sobre a questão da saúde física mostram que a omissão de informação é frequente, pois em $90(46,63 \%)$ casos não havia 
informação e estas foram obtidas na leitura dos depoimentos das vítimas.

Os estudos demonstram que as experiências associadas com eventos traumáticos estão intimamente ligadas com reações fisiológicas e, ao longo do tempo, com alterações no sistema biológico do estresse, pois o estresse muito intenso ou prolongado tem sido associado a alterações químicas como níveis mais altos de norepinefrina, dopamina, epinefrina e cortisol (Margolin \& Vickerman, 2007). O cérebro das crianças ainda está em desenvolvimento e é o órgão mais vulnerável a esses efeitos negativos no neurodesenvolvimento (Maia, 2010). Quanto ao aspecto psicológico, uma das reações à violência ou a eventos traumáticos gira em torno do afeto negativo. As reações emocionais oscilam e as consequências da desregulação afetiva incluem a dificuldade de lidar com as emoções, um afeto inadequado e problemas de relacionamentos que podem prejudicar a maturação e perturbar a criança no seu desenvolvimento e atividades normais (Margolin \& Vickerman, 2007).

A leitura dos casos e processos dá uma breve noção dos impactos físicos, psicológicos e comportamentais, pois em alguns casos havia informações sobre o estado físico e emocional dessas vítimas.

Este estudo verificou que a informação sobre as consequências imediatas para a saúde são, sobretudo, lesões físicas, o que é natural, uma vez que as agressões físicas são frequentes. As pesquisas sobre as consequências para a saúde mostram que as grandes doenças na idade adulta com as isquêmicas do coração, o câncer, doença pulmonar crônica, síndrome do intestino irritável e fibromialgia estão relacionadas com as experiências de abuso e violência durante a infância. Essas seriam as consequências na saúde em longo prazo (Maia, 2006). Além do efeito biológico das hormonais de estresse, um mecanismo que explica esses resultados é a adoção, por parte das vítimas, de comportamentos de risco - como tabagismo, abuso de álcool, má alimentação e falta de exercício (WHO, 2002).

Outras consequências são queixas físicas, algumas das quais podem constituir somatização, ou seja, ter alguma dimensão psicológica. Em termos psicológicos, a maioria das informações encontradas relata vítimas em estado de choque, com medo e dificuldades para dormir e alimentar-se. Segundo os critérios do DSM-IV (APA, 2004), a resposta a um evento traumático inclui medo, uma responsividade diminuída ao mundo externo, dificuldades de dormir, irritabilidade, dificuldade de concentração, sentimentos de culpa, respostas que foram encontradas

no estudo. Isso significa que, muito provavelmente, algumas das vítimas terão desenvolvido transtorno de estresse pós-traumático.

Em suma, este estudo procurou caracterizar os casos de denúncias de situações de violência, embora se saiba que os casos conhecidos são apenas uma pequena parte da realidade. Os dados deste estudo mostram a necessidade de introduzir mudanças nas formas de registros e de organizar serviços que possam apoiar as vítimas. $\mathrm{O}$ que deveria estar acontecendo é, como afirmaram Martins e Jorge (2009, p. 317), um:

\begin{abstract}
... atendimento que integre os serviços existentes, priorizem políticas para enfrentamento e redução da violência, viabilizem recursos e possibilitem melhorar a qualidade do atendimento e tratamento, proporcionando meios e estratégias que realmente sejam capazes de identificar e interromper as agressões praticadas contra a criança e o adolescente. Há uma necessidade de verificar o quadro de recursos humanos dessas instituições sobre as seguintes questões: pouco qualificados, precariamente remunerados e bastante reduzidos para atender a essa demanda, para estabelecer mecanismos de controle sobre o problema e para exercer ações preventivas e de atendimento das crianças e jovens vítimas de violência.
\end{abstract}

\section{CONSIDERAÇÕES FINAIS}

Citamos na introdução deste trabalho o modelo conceitual bioecológico de Brofenbrenner (1979) e Bronfenbrenner e Morris (1998) para dar conta dos níveis em que se podem considerar os fatores que contribuem para os fenômenos de violência. Várias características do contexto onde foi feito este estudo uma área a sofrer várias mudanças econômicas e sociais, com alterações demográficas acentuadas contribuirão para explicar os fenômenos de violência observados nos registros oficiais, embora reconheçamos as limitações de um estudo que se baseia em denúncias e em dados que dizem tanto sobre factos como sobre omissões.

Em sociedades nas quais a economia não se modernizou, mas se observam pontuais fenômenos de mudanças aceleradas, como é o caso do Interior da Amazônia, o abandono das atividades tradicionais levou à desintegração das formas de vida e das relações das pequenas comunidades, organizadas em torno da pequena agricultura, da pesca e da coleta. 
Essas modificações, associadas à falta de equipamentos urbanos e de assistência, favoreceram a intensa concentração populacional nos espaços considerados urbanos, conforme registra o relatório Situação Mundial da Criança (UNICEF, 2012) mais de $50 \%$ da população mundial - aí incluído mais de um bilhão de crianças e adolescentes - vivem hoje em cidades médias e grandes, e a um grande número delas é negado o acesso aos serviços de saúde, de educação, de recreação e de condições básicas de vida. Se a estes fatores de risco se juntarem fatores individuais como história anterior de violência, consumo de substâncias, problemas como pobreza ou instabilidade econômica, e fatores sociais como relações de vizinhança instáveis, e ainda fatores culturais que validam e aceitam a violência, encontramos um potencial de relações violentas.

Embora mudanças no nível dos valores tornem o cidadão cada vez mais consciente da inadmissibilidade da violência (especialmente quando as vítimas são crianças e adolescentes), há muito percurso a fazer. Por exemplo, a ausência de dispositivos institucionais, como o Juizado Especial, voltado para a Criança e Adolescente, favorece os agressores, que, na maior parte dos casos, não sofrem qualquer sanção. Por outro lado, a inexistência de órgãos de apoio e de ações de acompanhamento às crianças e adolescentes vítimas de violência torna muita vezes inconsequente, também para a vítima, a denúncia da violência. Por outro lado, devido a crenças que normalizam a violência, a disposição da população em denunciar esses casos ainda enfrenta a resistência cultural.

Persiste também o fato de muitos desses direitos ainda não serem identificados ou conhecidos da população, apesar de, no plano do discurso oficial, dos pesquisadores e das organizações internacionais, haver preocupações em tornar cada vez mais claras as condições e os dispositivos de combate à violência, advertindo para as suas consequências.

Estabelecemos como principal objetivo deste estudo a caracterização dos casos denunciados de violência contra crianças e adolescentes. Assim, em vez de um foco teórico, nosso objetivo era contribuir para melhor compreender, a partir de factos, este tipo de violência, e deste modo, fundamentar medidas que possam promover mudanças que protejam as vítimas e, principalmente, ajudar a promover programas de prevenção da sua ocorrência. A primeira conclusão é que os resultados deste estudo mostram a necessidade de padronizar os registros, coletando todas as informações necessárias para ser possível entender e prevenir esse processo de violência.
Além de mudar as regras sobre a forma e o conteúdo dos registros, os técnicos envolvidos nestas funções devem ter formação adequada para saber atender as vítimas e recolher a informação de uma forma que não as revitimize. Por outro lado, em muitos casos a pesquisa nesta área exige a utilização de outras fontes, especialmente quando se pretende compreender as consequências para a saúde. Assim, para a melhor obtenção de dados reais da situação da violência, faz-se necessário utilizar fontes alternativas de informação, como as unidades de saúde.

É preciso avançar no sentido de desvendar o problema, oferecer mais subsídios para interferir nas consequências deixadas pela violência, prevenir e identificar mais rapidamente o problema e realmente atender as vítimas e suas famílias. Além de a falta de dados credíveis tornar difícil a tomada de decisões sobre os problemas sociais, não é suficiente saber estatisticamente quantas são as vítimas e suas idades: é preciso compreender os efeitos que a violência causa sobre as vítimas e os prejuízos a elas imputados, e agir sobre eles. Essa é a parte mais frágil dos programas das instituições.

A violência pode ser prevenida. Exemplos de sucesso podem ser encontrados ao redor do mundo, com esforços da sociedade, das políticas nacionais e de iniciativas legislativas. (WHO, 2002). A saúde pública é, acima de tudo, caracterizada pela sua ênfase na prevenção. Ao invés de simplesmente aceitar ou reagir à violência, seu ponto de partida é a convicção de que o comportamento violento e suas conseqüuências podem ser evitados.

Em suma, não há um modelo pronto e acabado capaz de resolver de vez o problema da violência: o que existe são vários caminhos a serem percorridos, todos eles priorizando a ação conjunta do governo e da sociedade, aliada à solidariedade e à cooperação.

\section{REFERÊNCIAS}

American Psychiatric Association (2004). Diagnostic and statistical manual of mental disorders. (4a ed). Washington, DC: Author.

Ballone, G. J. (s.d). PsiqWeb, psiquiatria geral. DSM-IV. Recuperado em 02 de março, 2011 de, http://virtualpsy.locaweb.com.br/dsm.php?ltr=E

Barreto, M. G. (2009). Relatório TXAIN A violência sexual nos espaços cotidianos: Coari, Parintins e Tabatinga, de 1990 a março de 2003. Agência uga uga de comunicação. Manaus: Impresso.

Bezerra, S. C. (2006). Estatuto da Criança e do Adolescente: Marco da Proteção Integral. In C. A. Lima (Coord.), Violência faz mal à saúde (pp. 17-22). Brasília, DF: Ministério da Saúde. 
Brasil. Ministério da Saúde (2005). Secretaria de Vigilância em Saúde. Impacto da violência na saúde dos brasileiros. Brasília, DF, Ministério da Saúde. Recuperado em 12 de outubro, 2010 de, http://bvsms.saude.gov.br/bvs/publicacoes/impacto_viol encia.pdf.

Bronfenbrenner, V. (1979). The ecology of human development: experiments by nature and design. Cambridge, MA, Harvard University Press.

Bronfenbrenner, U., \& Morris. P. A. (1998). The ecology of developmental processes. In W. Damon \& R. M. Lerner (Eds.), Handbook of child psychology: Theoretical models of human development (Vol.1, pp. 993-1027). New York: John Wiley \& Sons.

Carvalho, C. M. (2010). Violência infanto-juvenil, uma triste herança. In M. G. B. Almeida. (Org.), A violência na sociedade contemporânea. Porto Alegre: EdiPUCRS.

Cecconello A. M., \& Koller, S. H. (2003). Inserção ecológica na comunidade: uma proposta metodológica para o estudo de famílias em situação de risco. Psicologia: Reflexão e Crítica, 16, 515-524.

Childhood Brasil (s.d). Foco no abusador: para evitar a reincidência. 29 out. Recuperado em 13 de maio, 2011 de, http://www.childhood.org.br/foco-no-abusadorpara-evitar-a-reincidencia.

Dahlberg, L. L., \& Krug, E. G. (2002). In World report on violence and health. In E. G. Krug, L. L. Dahlberg, J. A. Mercy, A. B. Zwi, \& R. Lozano (Eds.), World Health Organization: Geneva. Recuperado em 29 de Novembro, 2010, de http://www.opas.org.br/cedoc/hpp/ml03/0329.pdf

De Antoni, C., \& Koller, S. H. (2010). Uma família fisicamente violenta: uma visão pela teoria bioecológica do desenvolvimento humano. Temas em Psicologia, 18, $17-30$

Finkelhor, D. (1994). The international epidemiology of child sexual abuse. Child Abuse \& Neglect, 18, 409417.

Finkelhor, D., Ormrod, R., Turner, H., \& Hamby, S. L. (2005). The victimization of children and youth: A comprehensive, national survey. Child Maltreatment, $10,5-25$.

Gawora, D. (2003). Urucu. Impactos sociais, ecológicos e econômicos do projeto de petróleo e gás "Urucu" no Estado do Amazonas. Manaus: Editora Valer.

Hayasida, N. (2005). Gestão, Poder e Violência na Escola, Manaus. Dissertação de mestrado Não-Publicada, Programa de Pós-Graduação em Psicologia, Universidade Federal do Amazonas, Manaus, Amazonas, Brasil.

Instituto Brasileiro de Geografia e Estatística (IBGE) (2000). Censo Demográfico. Recuperado em 05 de fevereiro, 2011 de, http://www.ibge.gov.br/home/estatistica/populacao/cens o2000/universo.php?tipo=31o/tabela13_1.shtm\&pagina atual $=1 \&$ uf $=13 \&$ letra $=\mathrm{C}$
Lorenzi, G. W. (2007). Uma breve História dos Direitos da criança e do adolescente no Brasil. Recuperado em 11 de novembro, 2010 de, http://www.promenino.org.br/Ferramentas/Conteudo/ta bid/77/ConteudoId/70d9fa8f-1d6c-4d8d-bb6937d17278024b/Default.aspx\#1900

Machado, C., \& Dias, A. R. (2010). Abordagens culturais à vitimação: o caso da violência conjugal. In C. Machado (Coord.), Vitimologia: das novas abordagens teóricas às novas formas de intervenção (pp. 13-44). Braga: Psiquilibrios Edições.

Maia, A. (2006). Trauma, PTSD e saúde. In P. J. Costa, C. M., Lopes Pires, J. Veloso \& C. T. L. Pires (Orgs.), Stresse Pós-Traumático: modelos, abordagens \& práticas (pp. 21-33). Leiria: Editorial Diferença e ADFA.

Maia, A. (2010). Abordagens neuropsicológicas à vitimação. In C. Machado (Coord.), Vitimologia: das novas abordagens teóricas às novas formas de intervenção (pp. 81-102). Braga: PsiquilibriosEdições.

Margolin, G., \& Vickerman, K. A. (2007). Post-traumatic stress in children and adolescents exposed to family violence: I. Overview and Issues. Professional Psychology: Research and Practice, 38, 613-619.

Martins, C. B. G., \& Jorge, M. H. P. M. (2009). A violência contra crianças e adolescentes: Características epidemiológicas dos casos notificados aos Conselhos tutelares e programas de atendimento em município do Sul do Brasil, 2002 e 2006. Epidemiologia e Serviços de Saúde, 18, 315-334.

Ministério da Educação e Secretaria Especial dos Direitos Humanos (2004). Guia Escolar: métodos para identificação de sinais de abuso e exploração sexual de crianças e adolescentes. ( 2 a ed.) Brasília, DF. Recuperado em 05 de outubro, 2010 de, http://www.dhnet.org.br/dados/cartilhas/a_pdf_dht/carti lha_abuso_sexual.pdf

Ministério da saúde (2004). Violência faz mal a saúde. Brasília, DF. Recuperado em 29 de Setembro, 2010 de, http://dtr2001.saude.gov.br/editora/produtos/livros/pdf/ 06_0315_M.pdf

Piaget, J. (1936). A representação do mundo na criança. Rio de Janeiro: Record.

Poletto, M., \& Koller, S. H. (2008). Contextos ecológicos: promotores de resiliência, fatores de risco e de protecção. Estudos de Psicologia,25, 405-416.

Prati, L. E., Couto, M. C. P. P., Moura, A., Poletto, M., \& Koller, S. H. (2008). Revisando a Inserção Ecológica: uma proposta de sistematização. Psicologia: Reflexão $e$ Crítica, 21, 160-169.

Prómenino, (s.d). Um retrato atual do sistema de garantia de direitos. Instituto Latino Americano das Nações Unidas para Prevenção do Delito e Tratamento do Delinqüente (Ilanud). Fundação Telefonica. Recuperado em 29 de abril, 2011 de, http://www.promenino.org.br/Ferramentas/Conteudo/ta bid/77/ConteudoId/ea088c90-8c52-45b7-949d819886e237bf/Default.aspx 
Sevá, O., \& Iglesias, M. P. (2007). Impactos Sociais:Papo de índio. Recuperado em 10 de março, 2011 de, http://www.fem.unicamp.br/ seva/papodeindio_triplo_1 8abril07.pdf

Souza, E. R., \& Minayo, M. C. S. (1994). O impacto da violência social na saúde pública do Brasil; Década de 80. Rio de Janeiro: Centro Latino Americano de Estudos Sobre Violência e Saúde, Escola Nacional de Saúde Pública, Fundação Oswaldo Cruz. (Mimeo.)

UNICEF (2012). Situação Mundial da Criança: Crianças em um mundo Urbano. Brasília, DF: UNICEF.

Weaver, T. L., \& Clum, G. A. (1995). Psychological distress associated with interpersonal violence: A metaanalysis. Clinical Psychology Review, 15, 115-140.
World Health Organization (2002). World report on violence and health. In E. G. Krug, L. L. Dahlberg, J. A. Mercy, A. B. Zwi, \& R. Lozano (Eds.). World Health Organization: Geneva. Recuperado em 29 de Novembro, 2010 de, http://www.opas.org.br/cedoc/hpp/ml03/0329.pdf

Recebido em 15/11/2011

Aceito em 28/05/2012
Endereço para correspondência:
Angela Costa Maia. Centro de Investigação em Psicologia. Escola de Psicologia. Universidade do Minho. Campus de Gualtar, 4710-057, Braga, Portugal.E-mail: angelam@psi.uminho.pt. 